\title{
Intrauterine insemination: a retrospective review on determinants of success
}

\author{
Pramila Koli $^{1}$, Anil $M^{2}$, N R Ramya ${ }^{1}$, Kamal Patil ${ }^{1}$, M K Swamy ${ }^{1}$
}

\begin{abstract}
${ }^{1}$ Dept. of Obstetrics and Gynecology, ${ }^{2}$ Dept. of Biochemistry, Jawaharlal Nehru Medical College, Nehru Nagar, Belgaum-590010, Karnataka, India
\end{abstract}

Received: 20 April 2013

Accepted: 10 May 2013

\section{* Correspondence:}

Dr. Pramila Koli,

E-mail: pramilabk@yahoo.co.in

(C) 2013 Koli P et al. This is an open-access article distributed under the terms of the Creative Commons Attribution Non-Commercial License, which permits unrestricted non-commercial use, distribution, and reproduction in any medium, provided the original work is properly cited.

\begin{abstract}
Background: To determine the prognostic factors such as female patient's characteristics and of semen parameters on the pregnancy rate following intrauterine insemination

Methods: This study was done at Assisted Reproduction Centre, KLE's Hospital and Medical Research Centre, Belgaum, India between June 2011 to May 2012. A total of 264 IUI cycles in which clomiphene citrate with or without human menopausal gonadotropin was used for ovarian stimulation were analysed retrospectively to identify prognostic factors regarding treatment outcome.

Results: In this study the pregnancy rate was $17.25 \%$. The logistic regression analysis of variables showed that number of follicles and total IUI cycles were significantly associated with success rate but age of the couple, duration of infertility, endometrial thickness, size of the follicles, sperm count and sperm motility did not show significant differences between pregnant and non pregnant women.

Conclusions: The findings of this study showed that age of the couple, duration of infertility, endometrial thickness, size of the follicles, sperm count and sperm motility did not correlate with pregnancy occurrence in an IUI cycle but number of follicles and total IUI cycles correlated with the occurrence of pregnancy.
\end{abstract}

Keywords: Infertility, IUI (intrauterine insemination), Pregnancy

\section{INTRODUCTION}

Most couples seeking infertility treatment are subfertile and IUI is the first effective treatment chosen for suitably selected patients. IUI is the mode of treatment in infertility due to cervical factor, ovulatory dysfunction, endometriosis, immunological causes, male factor and unexplained infertility. ${ }^{1,2,3}$ IUI is less invasive, cost effective and an intermediate step before the application of sophisticated assisted reproductive technologies (ART) such as invitro fertilization (IVF) with or without intracytoplasmic sperm injection (ICSI). ${ }^{4}$

The success rate of IUI depends on several factors with pregnancy rates ranging from as low as $5 \%$ to as high as $70 \%$ per patient; however, a $10-20 \%$ clinical pregnancy per cycle is an acceptable range for all aetiologies. IUI may be performed in natural cycle as well as in combination with controlled ovarian hyperstimulation $(\mathrm{COH})$. When used in conjunction with $\mathrm{COH}$ in unexplained infertility, cumulative pregnancy rates may approach those of ART. ${ }^{5,6}$

In this retrospective study we have attempted to identify prognostic factors for the chance of pregnancy. These data would help clinicians in planning infertility treatment and predicting the success rate of IUI in individual couples.

\section{METHODS}

This study was approved by the Research Ethics Board of KLE University's Jawaharlal Nehru Medical College, Belgaum, India. In this retrospective study, we reviewed 
the medical records of women who underwent IUI at Assisted Reproduction Centre, KLE's Dr Prabhakar Kore hospital and medical research centre, Belgaum between June 2011 to May 2012. Records of 58 women who had undergone 264 IUI cycles using sperm from their partners were reviewed. Patients were excluded based on the lack of sufficient treatment data.

All subjects were couples for therapeutic IUI for the treatment of unexplained infertility, mild sperm dysfunction and anovulation. The study couples with at least one year of infertility underwent a basic infertility evaluation consisting of precise history taking, detailed clinical examination, laboratory test (prolactin and thyroid hormone concentration), tubal patency tests with hysterosalpingography (HSG)/ laparoscopy and uterine cavity evaluation with HSG/ hysteroscopy. Among women with infertility of less than two years or intrauterine pregnancy in the immediate past and no history suggestive of tuboperitoneal disease, tubal and uterine cavity evaluation was not always carried out before the first IUI treatment. However, tubal patency test was done if pregnancy did not occur after 2-3 cycles of IUI. The couples with tubal and severe male factor infertility (progressive motile sperm count $<1$ million $/ \mathrm{ml}$ ) and endocrine diseases were excluded from the study.

Male factor infertility was defined as: (i) a sperm count of $<20$ million/ml; (ii) normal morphology $<30 \%$ or (iii) progressive motility (grade $\mathrm{A}+\mathrm{B}$ ) $<40 \%$ before sperm preparation modifying World Health Organisation guidelines (1989)

The two methods of ovarian stimulation used in our study were: (i) administration of 50-100 mg clomiphene citrate (CC) from day 3 to 7 of the cycle; (ii) administration of $\mathrm{CC}$ and human menopausal gonadotropin ( $\mathrm{HMG}+\mathrm{CC}$ ), $\mathrm{CC}$ was prescribed from day 3 to 7 and intramuscular injection of 75mg of HMG on day 5,7 and 9.

Ovarian and endometrial responses were monitored using transvaginal sonography on day 9 to 13 . All subjects were given intramuscular injection of 5000 IU human chorionic gonadotrophin (HCG) when atleast one dominant follicle was $>17 \mathrm{~mm}$. IUI was performed 36 hours after administration of HCG using a simple IUI catheter under ultrasound guidance. IUI was repeated the next day if the follicle had not ruptured. A standard inseminate volume of one $\mathrm{ml}$ prepared using swim up method was used. The patients were advised to rest for 20 min following IUI. Micronised progesterone vaginal pessaries (400mg bd) were prescribed for luteal phase support for 14 days post IUI.

The descriptive variables recorded were couple's age, duration of infertility, number of follicles, size of follicles, endometrial thickness, single/double IUI, number of IUI cycles, sperm concentration and sperm motility. The statistical analysis was done using SPSS statistical software (version 12). A logistic regression analysis method was used to identify significant variable that contribute to the success of IUI and to predict the probability of pregnancy for each cycle. $\mathrm{P}$ value $<0.05$ was considered to be of statistical significance.

\section{RESULTS}

A total of 264 IUI cycles were analysed. The overall pregnancy rate per cycle and per couple was $3.8 \%$ $(10 / 264)$ and $17.25 \%(10 / 58)$ respectively. IUI result according to female characteristics and sperm parameters (after preparation) are given in Table 1. The average female and male age was $26.4 \pm 5.35$ years and $33.6 \pm 4.9$ years respectively in the participants with positive IUI result. Both were not statistically significant. Duration of infertility, type of infertility, endometrial thickness, number of follicles, size of follicles, sperm count, sperm motility and single/double IUI did not significantly affect the outcome of IUI. However, logistic regression analysis showed significant relationship between pregnancy occurrence and number of follicles and number of IUI cycles (Table 2).

Table 1: IUI result according to female characteristic and sperm parameters (after preparation).

\begin{tabular}{|ll|ll|}
\hline Characteristic & $\begin{array}{l}\text { Pregnancy } \\
\text { positive }\end{array}$ & $\begin{array}{l}\text { Pregnancy } \\
\text { negative }\end{array}$ & $\begin{array}{l}\text { P } \\
\text { value }\end{array}$ \\
\hline $\begin{array}{l}\text { Female } \\
\text { age(years) }\end{array}$ & $26.4 \pm 5.35$ & $28.1+4.13$ & 0.248 \\
\hline $\begin{array}{l}\text { Male age } \\
\text { (years) }\end{array}$ & $33.6 \pm 4.9$ & $34.8 \pm 4.69$ & 0.464 \\
\hline $\begin{array}{l}\text { Duration of } \\
\text { infertility } \\
\text { (years) }\end{array}$ & $6.7 \pm 2.79$ & $7.5 \pm 4.15$ & 0.554 \\
\hline $\begin{array}{l}\text { Endometrial } \\
\text { thickness(mm) }\end{array}$ & $8.5 \pm 1.43$ & $8.7 \pm 2.83$ & 0.823 \\
\hline $\begin{array}{l}\text { Number of } \\
\text { follicles }\end{array}$ & $3.4 \pm 2.67$ & $2.0 \pm 1.16$ & 0.012 \\
\hline $\begin{array}{l}\text { Size of } \\
\text { follicles(mm) }\end{array}$ & $18.8 \pm 1.03$ & $19.2 \pm 7.75$ & 0.647 \\
\hline $\begin{array}{l}\text { Sperm count } \\
\text { (million/ml) }\end{array}$ & $35.50 \pm 12.12$ & $39.10 \pm 24.24$ & 0.64 \\
\hline $\begin{array}{l}\text { Sperm motility } \\
(\%)\end{array}$ & $41.00 \pm 11.00$ & $47.10 \pm 18.81$ & 0.380 \\
\hline $\begin{array}{l}\text { Number of IUI } \\
\text { cycles }\end{array}$ & $2.00 \pm 1.05$ & $3.8 \pm 1.92$ & 0.006 \\
\hline
\end{tabular}

\section{DISCUSSION}

In this study we attempted to identify prognostic factors associated with success in clomiphene citrate / CC+HMG/ IUI treatment. We carried out logistic regression analysis of 264 IUI cycles and identified two significant variables: these are number of pre-ovulatory follicles and number of treatment cycles.

In our study the overall pregnancy rate for all cycles was $17.25 \%$ which is similar to the other studies. ${ }^{7,8}$ The 
fecundity rates for patients undergoing ovarian stimulation with IUI have varied from 7 to $29 \% .^{9-12}$ In Houmard et $\mathrm{al}^{9}$ study, the lower clinical pregnancy was attributed to higher maternal age and lower ovulatory disorder cases. These differences between other studies and ours are probably due to different causes of infertility, type of treatment and younger women seeking infertility treatment in our country.

Table 2: Logistic regression analysis.

\begin{tabular}{|lllll|}
\hline Variables & $x^{2}$ & SE & Beta & $\begin{array}{c}\text { 'p' } \\
\text { value }\end{array}$ \\
\hline Age of wife & 1.427 & 0.086 & 0.100 & 0.246 \\
\hline $\begin{array}{l}\text { Age of } \\
\text { husband }\end{array}$ & 0.591 & 0.082 & 0.061 & 0.458 \\
\hline $\begin{array}{l}\text { Duration of } \\
\text { infertility }\end{array}$ & 0.374 & 0.093 & 0.056 & 0.548 \\
\hline $\begin{array}{l}\text { Endometrial } \\
\text { thickness }\end{array}$ & 0.055 & 0.141 & 0.032 & 0.819 \\
\hline $\begin{array}{l}\text { Number of } \\
\text { follicle }\end{array}$ & 4.937 & -0.436 & 0.212 & 0.040 \\
\hline $\begin{array}{l}\text { Size of } \\
\text { follicles }\end{array}$ & 0.219 & 0.390 & 0.065 & 0.691 \\
\hline Sperm motility & 0.234 & 0.017 & 0.008 & 0.639 \\
\hline Sperm motility & 1.108 & 0.021 & 0.021 & 0.326 \\
\hline $\begin{array}{l}\text { Total IUI } \\
\text { cycles }\end{array}$ & 9.126 & 0.320 & 0.763 & 0.017 \\
\hline
\end{tabular}

In this study, the average female and male age did not show any influence on IUI results. The advancing maternal age decreases female fecundity ${ }^{13}$ and this is due to reduced uterine receptivity ${ }^{14}$ and/ or decreased oocyte quality. However, the prognostic value of woman's age was not significant in studies undertaken by Brzechffa et $\mathrm{al}^{15}$ and Tomlinson et $\mathrm{al}^{16}$ which was similar to our study.

We did not find significant influence on pregnancy rate with an increasing duration of infertility as shown by other studies. ${ }^{17,18}$ However, various studies have shown duration of infertility as a significant prognostic factor. ${ }^{16,19}$ In our study, the number of follicles was a prognostic predictor of IUI outcome, which is similar to that found in earlier studies. ${ }^{20,21}$ The positive relationship between follicle count and IUI success could be due to increased chances of fertilization and implantation. Sperm count and progressive motility after preparation were not indicator of IUI success. This is due to sperm screening prior to IUI and exclusion of couples with a progressively motile sperm count of $<1$ million $/ \mathrm{ml}$.

In the present study number of treatment cycles was a good prognostic indicator and the pregnancy chances were highest in first two treatment cycles. In the literature, the decreasing pregnancy rates with an increased number of treatment cycles have also shown similar to our results. ${ }^{8,22}$ The number of treatment cycles should be limited in women $>40$ years and severe male factor infertility.

Insemination frequency (single/double IUI) did not show significant impact on IUI outcome. Several studies ${ }^{23,24}$ showed increased probability with double IUI compared to single IUI.

The cost effectiveness of the treatment is important in making decision regarding different treatment options. In our hospital the cost of IVF treatment is over five fold higher compared to $\mathrm{CC} / \mathrm{CC}+\mathrm{HMG} / \mathrm{IUI}$. In addition longer time off work and higher multiple pregnancy rates following IVF treatment further favours the costeffectiveness of IUI treatment.

The principal weakness of this study, in addition to the fact that it is a retrospective study and not randomized, is the small number of subjects.

\section{CONCLUSION}

Clomiphene citrate/ CC+HMG/ IUI is a useful and cost effective treatment option for infertility. We find that two variables have significant prognostic value with regard to IUI success: number of follicles and number of treatment cycles. Careful patient selection criteria along with successful ovarian stimulation enhances the treatment outcome. This information will help us in counseling infertile couple and make it possible to carry out more precise patient selection, preventing any wasteful and unnecessary treatment and increase the cost-effectiveness of IUI therapy.

\section{REFERENCES}

1. Alborzi S, Motazedian S, Parsanezhad ME, Jannati S. Comparison of the effectiveness of single IUI versus double IUI per cycle in infertile patients. Fertil Steril. 2003; 80: 595-599.

2. Bry-Gauillard H, Coulondre S, Cedrin-Durnerin I, Hugues JN. Benefits aand risks of ovarian stimulation before IUI. Gyn Obs Fert. 2000; 28(11): 820-831.

3. Manganiello PD, Stern JE, Stukel TA, Crow H, Brinck-Johnsen T, Weiss JE. A comparison of clomiphene citrate and human menopausal gonadotrophin for use in conjunction with intrauterine insemination. Fertil Steriil. 1997; 68(3): 405-412.

4. Oehninger S. Place of intracytoplasmic sperm injection in management of male infertility. Lancet. 2001; 357: 2068-2069.

5. Hannoun, A., Abu-Musa, A., Kaspar, H. and Khalil, A. Intrauterine insemination IUI: the effect of ovarian stimulation and infertility diagnosis on pregnancy outcome. Clin. Exp. Obstet. Gynecol. 1998 ;25: 144-146.

6. Goverde, A.J., McDonnell, J., Vermeiden, J.P., Schats, R., Rutten, F.F. and Schoemaker, J. 
Intrauterine insemination or in-vitro fertilization in idiopathic subfertility and male subfertility: a randomized control trial and cost effectiveness analysis. Lancet. 2000; 355: 13-18.

7. Mehrafza M, Nobakhti N, Atrkar Roushan Z, Dashtdar H, Oudi M Hosseini A. The correlation of semen parameters and pregnancy outcome after intrauterine insemination. Iranian Journal of Reproduction Medicine. 2003;1(1); 29-32.

8. Paul Y S Tay, V R Mohan Raj, A Kulenthran, O Sitizawiah. Med J Malaysia. 2007;62(4): 286-289

9. Houmard BS, Houmard M, Peter J. Factors influencing pregnancy rates with a combined clomiphene citrate/gonadotropin protocol for nonassisted reproductive technology fertility treatment. Fertil Steril. 2002; 77: 384-386.

10. Richard P, Taylor SN, Lu P, Sartor BM, Pyrzak R. Clomiphene citrate intrauterine insemination (IUI) before gonadotropin IUI affects the pregnancy rate and the rate of high-order multiple pregnancies. Fertil Steril. 2004; 81: 345-48.

11. Werkrouck E, Spiessens C, Meulemen C, D’Hooghe $\mathrm{T}$. No difference in cycle pregnancy rate and cumulative pregnancy live-birth rate between women with surgically treated minimal to mild endometriosis and women with unexplained infertility after controlled ovarian hyperstimulation and intrauterine insemination. Fertil Steril. 2006; 86: 566-71.

12. Dmowski WP, Pry M, Ding J, Rana N. Cyclespecific and cumulative fecundity in patients with endometriosis who are undergoing controlled ovarian hyperstimulation and intrauterine insemination or in vitro fertilization-embryo transfer. Fertil Steril. 2002; 78: 750-56.

13. Kang B M, Wu T C. Effect of age on intrauterine insemination with frozen donor sperm. Obstet Gynecol. 1996; 88: 93-96.

14. Cano F, Simon C, Remohi J, Pellicer A. Effect of aging on the female reproductive system: evidence for a role of uterine senescence in the decline female fecundity. Fertil Steril. 1995; 64: 584-58915 (3). Navot D, Bergh P A, Williams M A. Poor oocyte quality rather than implantation failure as a cause of age-related decline in female fertility. Lancet. 1991; 337: 1375-1377.

15. Brzechffa PR, Buyalos RP. Female and male partner age and menotrophin requirements influence pregnancy rates with human menopausal gonadotrophin therapy in combination with intrauterine insemination. Hum Reprod. 1997; 12: 29-33.

16. Tomlinson M J, Amissah-Arthur J B, Thompson $\mathrm{K}$ A. Prognostic indicators of intrauterine insemination(IUI): statistical model for IUI success.Hum Reprod. 1996; 11: 1892-1896.

17. Zahra Basirat, Seddigheh Esmaeilzadeh. Prognostic factors of pregnancy in 500 cases of intrauterine insemination in Babol, northern Iran. Royal Institute International Journal of Fertil and Steril. 2010; 4(1): 35-39.

18. Iberico G, Vioque J, Ariza N, Lozano JM, Roca M, Liacer J. Analysis of factors influencing pregnancy rates in homologous intrauterine insemination. Fertil Steril. 2004; 81(5): 1308-1313.

19. Crosignani P G, Walters D E, Soliani A. Clinical pregnancy and male subfertility; the ESHRE multicentre trial on the treatment of male infertility. Hum Reprod. 1994; 9: 1112-1118.

20. Tur R, Barri P N, Coroleu B, Buxaderas R, Martinez F, Balash J. Risk factor for high order multiple implantation after ovarian stimulation with gonadotropin. Hum Re prod. 2001; 16(10): 21242129.

21. Montanaro Gauci M, kruger T F, Coetzee K, Smith K, Van Der Merwe J P, Lombard C J. Stepwise regression analysis to study male and female factors impacting on pregnancy rate in an intrauterine insemination programme. Andrologia. 2001; 33(3): 135-141.

22. Burr RW, Siegberg R, Flaherty SP. The influence of sperm morphology and the number of motile sperm inseminated on the outcome of intrauterine insemination combined with mild ovarian stimulation. Fertil Steril. 1996; 65: 127-132.

23. Ransom M X, Blotner MB, Bohrer M, Corsan G and Kemmann E. Does increasing frequency of intrauterine insemination improve pregnancy rates significantly during superovulation cycles? Fertil Steril. 1994; 61: 303-307.

24. Ragni G, Maggioni P, Guermandi E, Testa A, Baroni E, Colombo M and Crosignani PG. Efficacy of double intrauterine insemination in controlled ovarian hyperstimulation cycles. Fertil Steril. 1999; 72: 619-622.

DOI: $10.5455 / 2320-1770$. ijrcog20130910

Cite this article as: Koli P, M Anil, Ramya NR, Patil K, Swamy MK. Intrauterine insemination: a retrospective review on determinants of success. Int J Reprod Contracept Obstet Gynecol 2013;2:311-4. 